\title{
Road Map to Human Resources Management Practices in Organizations
}

\author{
Fahad Alqusumi \\ (Diaverum, Clinic Administrator, Saudi Arabia)
}

\begin{abstract}
The term HRM increasingly has been used in a wider context than the traditional notions of personnel and labour administration, and has attracted more researchers to examine its development.The human resource department advertises, recruits and trains people, giving them skills that are specific to the different organization. An organization with all the machinery needed to produce but lack the necessary human skills to use these machines cannot succeed. Contrary, organizations with the machines required for production and the necessary manpower will achieve their objectives. Manpower is the most significant aspect of organizational performance when it comes to machine operation. Realistically speaking, an organization with a well skilled human force can produce and make profits, unlike machines that cannot perform without an efficient human force. From the above analysis it can be seen clearly that human resource management has a big part to play in ensuring that an organization's goals have been met. Employee relations by Human resource management create an environment in which productive and harmonious relations can be maintained. Human resource management is the most important department for the following reason. This paper aims to gives a clear and comprehensive understating what are the crucial human resources management practices and why they are of extreme importance to organizations.
\end{abstract}

Keywords: Human Resources Management, Recruiting, Selection, Safety and Health, Training

\section{Human Resources Management Importance in the organizations}

Human Resource Management (HRM) is the function or a department within an organization that carries out recruitment, selection, management and provides direction and guidance for the employees or workforce in the organization. Line managers can also perform the work of human resource management (Armstrong, 2006).

It deals with issues related to employees such as training, hiring, compensation, wellness, benefits, performance management, communication and administration and organization development. Human resources are the individuals who comprise the employees, staff or workforce of an organization. Human resources are charged with the responsibility of formulating and implementing policies and strategies relating to the management of people (human resources) in an organization (Gubman, 1996).

From the definition of Human Resource Management (HRM), it is clear that, the department is important in an organization. The human resource management department determines the success or failure of an organization. For the set goals and objectives of an organization to be achieved, it is the human resources who determine whether they will be attained or not. This shows that, human resources are the driving force and the main pillars for the success of the organization. An organization can have assets and financial resources but if it lacks the committed and dedicated human resources to the management and to utilize the resources; then the organization may cease to exist due to the fact that, an organization exists because of people (human resources) (Johnston, 1996).

Even if an organization owns assets such as big buildings, large tracks of land, many vehicles and millions of money in the bank account; and there are no human resources to manage them, then the organization does not exist. This means that, human resources are the ones who make up the organization. This therefore explains partly why human resource management is an important department in any organization, institution, or company. It is the human resources who can build or destroy the image and reputation of an organization. This therefore clearly indicates how important the human resource management and should well established and developed in the organization (Armstrong, 2006).

All other departments in the organization depends on this department including sales and marketing, accounting, finance, production, research and development, credit and loans departments. Human resource management strategy in an organization is to maximize returns on investment in the human capital of the organization and to minimize financial risks that may face the human resources of the organization. Human resources seek to attain this by assigning the skilled, competent, and qualified people in the organization (Gubma, 1996).

Human resources with the current skills ensure that the business survive and succeed in future due to the Human Resource Management prudent strategies on how to face the future without fear. For these objectives 
to be achieved, the human resource management requires to implement the workforce requirements pragmatically and effectively by taking into account of ethical, legal, social and in a practical manner in order to maintain the support, unity, and respect of all workforces within the organization (Johnston, 1996).

Organizations have realized the importance of human resources and are looking for better ways of producing quality goods and services that satisfy its customers and potential customers. When new technology hit the market, the organization must adopt it so as to give it a competitive advantage over others; but this only is possible by having qualified human resources in the field of technology who can ensure the department is of importance to the whole organization(Reece 45). Technology is rapidly changing and it is the driving force for many organizations nowadays; therefore it means that, lack of the people to guide the organization's management on the important technology to be adopted, then, the organization may be outperform by its competitors or rivals in the market. This cannot be achieved without experts and professionals in the field to monitor who can guide on adopting and improving the new technologies (Gubman, 1996).

The growth in the human resource management department has ensured that the staff employed brings to the organization knowledge on new technology to the organization for him or her to be relevant and useful. For example, to be successful in the automotive company, the company through the human resource management department needs to hire highly skilled, dedicated, committed, innovative, creative, and flexible human resources who have the ability and capability to ensure the company maintains or improves its technology based on what is available in the market (Armstrong, 2006).

A talented human resource management department is needed for the organization to be well organized and to meet its targets within the stipulated time. Besides recruiting, selecting, and hiring qualified people to perform specific tasks and duties, the human resources department has to build a strong loyalty and commitment among the human resources. This will ensure the workforce are kept up to date on organizations' working conditions, laying down implications on job tenure, terms and security and keeping them understand the organization's plans (Gubman, 1996).

According to most authors of human resource books and journals, they all believe that, the backbone of successful and prosperous organization is the human resources management department. They also expressed their concerns that, without a talented team of experts to hire, inform and to culture employees, the organization is doomed for failure and closure. From experience, the HRM department knows everything about the weaknesses and strengths of all employees and what need to be done for a better and successful organization both in the present and in future. This cuts across all the small, medium, and large organizations globally (Reece and Rhonda, 1993).

Michael Armstrong in his book of human resource management articulated that, for the organizations or companies to succeed, the human resources must be linked to the personnel policies and procedures and should be monitored all the time for its effectiveness to be known. This is to ensure employee evaluation and appraisal is accurate and fair(Armstrong, 2006).

The HRM is important to the organization because it carry out job analysis before they recruit new employees. It determines with the help of other company functions the responsibilities and nature of various employment positions and vacancies. HRM department provides valid information the jobs and employee requirements for him or her to fill the vacant position. This means that, it is only the HRM department experts who knows who fits certain position and who is not. They anticipate the future training needs, wages and salary increment patterns and other crucial HRM decisions that my affect the organization's performance and sustainability in the competitive market. HRM is important in managing the flow of personnel within the organization by use of transfers, promotions, and demotions within and outside the organization. This makes the Human Resource Management department to ensure all stakeholders to the organization are satisfied (Green, 1999).

The department is also important in organizing, maintenance, and utilization of company's personnel. This involves planning an organizational framework and design that will ensure the organization make good use of the human resources and to develop systems of communication and coordination that will help the organization to carry out its operations in a unified manner (Marmer, 1993).

A safety, health, and worker management relation in an organization is an important aspect in HRM department within the organization. The HRM department maintains all the activities related to the safety and health of all employees. This entails complying with the federal laws and regulations that aims at protecting employees from hazards, risks or any other danger in the workplace that may affect the employee performance either mentally or physically.

The HRM knows the importance of ensuring the safety and well fare of its workforce. Injured or sick employees will not deliver or perform as expected in the organization leading to poor performance and production of poor quality products and services. This kind of scenario will make the customers and the potential customers to shy away from the products and services of the company (Green, 1999). 
A healthy worker translates to improved performance, quality goods, and services, which in the end lead to increased sales and profit margins. The HRM department collaborates with the health agencies that will continuously monitor the health conditions of all the workers in the organization (Marmer, 1993). The health and safety regulations are handed down from different agencies such as environmental protection agency (EPA), occupational safety and health administration (OSHA) and many other agencies that provide health support services in the organization. It is believed that, a health person is economical and productive at all times. This is another reason as to why the Human Resource Management is important in an organization. This is because the health services safety measures cuts across all departments in an organization (Rossiter 45).

Such health and safety provisions in an organization will ensure employees are compensated, protected, and secured all times. This department also works together with other bodies like labor unions in ensuring terms and conditions at the work place meets the required standards. It also handles cases such as misconduct, theft, sexual harassment and other forms abuses, which may occur at work place. The department fosters this by devising a well coordinated and communication system that will enhance cooperation, unity, teamwork and a shared sense of mission and vision among all employees in the organization (Marmer,1993).

Performance appraisal and evaluation falls squarely within the department of HRM and it is important in the organization. Assessing employees on their job performance is very critical in providing an elaborate feedback on employee performance both negative and positive performance. Performance evaluation and appraisal is an important aspect for both the person (employee) and organization. The results of the evaluation are used to determine the salary and wage increase which finance department would use to making the payment to the employee (Marmer, 1993).

Promotion and dismissal of an employee is determined by the experts in the department from any department in the organization. The officials at the HRM department coordinate and monitor all employees in the organization; therefore, employees who do not meet the department's expectations and requirements are referred back to the HRM department for action to be taken either to be fired or to be corrected by the disciplinary committee. This is a clear indication that, Human Resource Department is critical in the organization and in its failure to play its roles, the organization may not function any more (Reece and Rhonda, 1993).

Concerning reward system, best performers in the organization are picked from any department and this means the HRM department must know all the employees in all other departments so that the best employee can be picked in a just and a fair way. Rewards and compensations in the organization motivations and inspired employees; hence HRM experts and professionals play an important role in performance improvement, increased sales and profit margins and good company image and reputation(Carlotta and Gray, 2000).

Reward system will encourage poor performers because they will ashamed when top performers are being awarded with presents and prices either in monetary or in other forms. This is also a mechanism where the organization addresses some problems and challenges and to institute disciplinary measures and actions to those who go against the rules and regulations. In order for the organization to align the employees with the set goals and objectives, the department has to provide the employees with the appropriate relationship that will motivate them to identify themselves with the organization's strategic plan and ownership (Rossiter, 2000).

Another vital or important responsibility of Human Resource Management department is employee development and training, which is offered to all employees in the organization organized by the department. This is meant to improve the employee skills, knowledge, and competencies at the work place. The HRM department must therefore know the training needs of employees in each department before they conduct the training session so as to address those needs during meeting and training sessions organized as either a joined meeting or departmental meeting and training session (Carlotta and Gary, 2000).

The department evaluates employee development and training programs which are meant to boast employee morale. A good example is where the human resource management department ensures the information technology experts and other employees in other departments are trained on how to use the new technology so as to familiarize themselves with the new software (Green, 1999).

Human resource management has had significant impact on the broad field in all departments especially in the information dissemination and communication across all departments in the organization and has dramatically altered business operation in the global landscape (Johnston 30). HRM experts and professionals have had to develop new guidelines to deal with emerging issues in technology, satellite communication, networking system, computer, fax machines, and other devices used in the department to pass information to all employees in the organization. Human resource management has influenced the changing face of the organization management because of the continuous processes and procedures are adjusted to suit the needs of the clients and all stakeholders of the organizations (Rossiter, 2000). 


\section{Planning and development of organizations strategies}

Planning refers to deciding in advance what is to be done, by who and when. Strategies can be defined as the direction and scope of an organization over a long time which matches the organizations resources to its changing environment. The environment in this case refers to the customers, clients and markets to meet the needs of the owners of the business. Planning and developing strategies of an organization means deciding the direction it will take and the magnitude of its performance. The developed strategies are meant to match the organizations abilities and its resources. Talent management technologies have unquestionably become one of the best ways for companies and HR departments to drive better employee performance and enterprise success following the recession (U.S. HR Articles). This is enhanced by the human resource department making it one of the most important.

In spite of the initial costs, organizations are increasingly deploying new or enhanced systems, recognizing that efficient and effective HR processes enable the flexibility and agility employers need in an uncertain but growth-oriented business environment (U.S. HR Articles). For this reason the Human Resource department will deal with matching human resources with the opportunities in the environment as well. The department does this by ensuring that the people who work in the organization have skills that can maximize the available opportunities. The human resource department also sees to it that the human resource management strategies and the business strategies are in agreement. Correlation between human resource and business strategies are essential aspects of organizational performance. In addition, it ensures that the different elements of the strategies are supportive of each other in order to bring goal congruence in the organization. These strategies give an organization a sense of direction and employees a sense of purpose. This means that employees are fully aware of what they are expected to do and how to do it. This makes the human resource department one of the best in the organization.

The human resource management department does not stop at developing the strategies. It also monitors the performance of the strategies through employee feedback surveys. The monitoring is meant to check if the desired results match with the outcome of the strategy. If the results are not as desired, changes to the strategies should be made to be in line with the expectations. The planning and strategy development function of the human resource department has just emphasized how the department is the best in any given organization. The efficiency of an organization therefore can be traced back to the Human Resource Management department hence the importance.

Firstly, Recruitment refers to the process of inviting people, evaluating them and picking those with the desired qualifications for a job at an organization. Medium and large organizations may look for professional recruiters from outside the organization. Recruiting and selection is involved with specifying the requirements from each prospective employee, as well as preparing them for overseas assignments. The Hard version of Human resource management emphasizes that are important resources through which organizations achieve competitive advantage (Armstrong, 2006). These tasks are carried out by the human resource department making it the most important in any organization.

In addition to these adjustments, the employee should be ready to assimilate to foreign environments. Re-entry policies for overseas employees should be considered so that when they return from abroad, they should be given the same opportunities when it comes to promotion. After the specifications are made, they are advertised through the various media for the prospective employees' attention. Human Resource Management allows significant benefits as organizations can obtain more holistic views of workforce productivity and growth potential without time-consuming manual abstraction and collation of information (U.S. HR Articles).

Secondly, For employees to perform to the expected standards, they need to be equipped with the skills they will need in their jobs. Their 13th annual survey of HR service delivery trends and practices found that human resource departments are more confident than ever in the value and efficiency resulting from enhanced talent management systems (U.S. HR Articles). There are many reasons as to why employees should be trained. Employees are trained so as to fill gaps created when other employees leave the organization. Training is also important in equipping the employees with the knowhow of applying new technologies. Von Glinow and Teagarden, 1988, differentiate between the transfer of industrial technology (hard) and the transfer of management and marketing technologies (soft) (Thompson 137). Large corporations use Human Resource Information Systems (HRIS) extensively and more and more providers are addressing the potential of webbased HRMS solutions for medium and smaller businesses (U.S. HR Articles). The technology involved in HRIS cannot be effective without incorporating human resource management hence the reason why the human resource department is the most important in the organization.

Employee training also plays a part in enhancing employee effectiveness, efficiency and motivation. Motivation is one of the key factors in boosting employee performance. Organizations need to train their employees so as to expand and incorporate new programs. The training of employees leads to increased productivity, reduced employee turnover, increased efficiency that leads to financial gains to the organization and decreased need for supervision. Zhu et al. (2008) focused on the transfer of training competencies in the 
electronics industry in China and concluded that improved performance was a benefit of training, managerial follow-up was a key aspect of training, and that the Western management system of organizing the workplace was perceived as effective.

An organization requires a set of procedures in training of employees so as to create efficiency. The first procedure for the organizations should involve identifying the potentials of the organization and what it does best with the current employees. The organization should also check on the availability of finances for training. It would not be advisable to start training without adequate funds. The organization should specify where training is required. It would not be possible to train all employees. The areas within the organization requiring urgent needs should be considered for training first. Training is one of the most important factors carried out by the human resource management making it the most important in the organization.

\section{Conclusion}

In conclusion, the human resource management is important because, as per the many authors of the human resource books and articles, all writers agree that, without the human resources in an organization, then that is not an organization. This therefore means that, Human Resource Management department is the pillar or the cornerstone in the success of any organization, business, or company. Though other resources are important, the people or the human resources carry more weight (Johnston, 1996).

\section{References}

[1] Armstrong, M.(2006). A Handbook of Human Resource Management Practice. New York: Kogan, Page Limited, (2) 45-70

[2] Carlotta, R., \& Gary, S.(2000). Human Resources Management. Washington, D.C.: Small Business Administration, (2) 78-90.

[3] Green, P.(1999). Building Robust Competencies: Linking Human Resource Systems to Organizational Strategies. New York: Jossey-Bass, 80-95.

[4] Gubman, E. L.(1996). The Gauntlet is down. Journal of Business Strategy, (2) 50-56.

[5] Johnston, J.(1996). Time to Rebuild Human Resources. Business Ouarterly, (5) 23-35.

[6] Reece, B. L., \& Rhonda, B.(1993). Effective Human Relations in Organizations. Boston: Houghton Mifflin, (3) 45-68.

[7] Rossiter, J. A. (2000). Human Resources: Mastering Your Small Business. New York: Upstart Publishing.

[8] Marmer, C. (1993). Working Smarter: How HR Can Help. Personnel Journal, (2) 24-30.

[9] Zhu C.J., S. Thomson B. and De Cieri H. (2008). A retrospective and prospective analysis of HRM research in Chinese firms: Implications and directions for future study, Human Resource Management, 133-156,

[10] http://www.hrmguide.com/technology/hr-technology-survey.htm, HR Executives Making More Of Technology, U.S. Human Resource Articles. http://www.hrmguide.com/technology/hr-technology-awards.htm, Integrating HR Technology, U.S. HR Articles. 